\title{
Resistência genotípica e monitoramento da favorabilidade para ocorrência da ferrugem alaranjada da cana-de-açúcar ${ }^{1}$
}

\author{
Kelly Lana Araújo ${ }^{2}$, Marcelo Giovanetti Canteri ${ }^{3}$, Thiago Alexandre Santana Gilio ${ }^{4}$, Rafael Altrão Neubauer ${ }^{5}$ Paulo \\ Bonfim Sanches ${ }^{6}$, Ciro Hideki Sumida ${ }^{7}$, Éder Antônio Giglioti ${ }^{8}$
}

${ }^{1}$ Projeto Financiado pelo MAPA/CNPq (578790/200 8-4); ${ }^{2}$ Bolsista Capes PNPD, Universidade Estadual de Londrina; ${ }^{3}$ Prof. Dr. da Universidade Estadual de Londrina; ${ }^{4}$ Discente de Agronomia da Faculdades Adamantinenses Integradas, Bolsista CNPq DTI 3; ${ }^{5}$ Engenheiro Agrônomo, Bolsista CNPq ITI A, Universidade Estadual de Londrina; ${ }^{6}$ Discente de Agronomia da Faculdades Adamantinenses Integradas; ${ }^{7}$ Bolsista Capes PNPD, Universidade Estadual de Londrina; ${ }^{8}$ Centro Nacional de Pesquisa em Agroenergia - CNPAE/Embrapa Agroenergia.

Autor para correspondência: Ciro Hideki Sumida (cirosumida@ hotmail.com)

Data de chegada: 24/06/2013. Aceito para publicação em: 07/10/2013.

1898

\section{RESUMO}

Araújo, K.L.; Canteri, M.G.; Gilio, T.A.S.; Neubauer, R.A.; Sanches, P.B.; Sumida, C.H.; Giglioti, E.A. Resistência genotípica e monitoramento da favorabilidade para ocorrência da ferrugem alaranjada da cana-de-açúcar. Summa Phytopathologica, v.39, n.4, p.271-275, 2013.

A ferrugem alaranjada é atualmente uma das principais doenças da cana-de-açúcar. Redução na produtividade de genótipos suscetíveis e intermediários superiores a $40 \%$ foram registradas em muitos países, inclusive no Brasil. Este trabalho foi desenvolvido com o objetivo de monitorar os principais genótipos de cana-de-açúcar plantados no Brasil, sob alta pressão de inóculo, quanto à ocorrência e ao desenvolvimento da ferrugem alaranjada. O experimento foi conduzido em área experimental da Usina Univalem, do Grupo Raízen S.A., localizada em Valparaíso (SP). O delineamento experimental utilizado foi em blocos casualizados, com 38 tratamentos (genótipos) e quatro repetições. Cada parcela foi constituída por três linhas de cinco metros, espaçadas de $1,4 \mathrm{~m}$. Entre cada parcela foi incluída uma linha do genótipo CV14, suscetível à ferrugem alaranjada. A partir da emergência das plantas, todas as parcelas foram monitoradas mensalmente para determinar o início do aparecimento dos sintomas da doença. Depois de constatados os primeiros sintomas, a severidade da ferrugem alaranjada foi quantificada mensalmente na folha +3 em três plantas por parcela. Os meses mais favoráveis para ocorrência da doença foram Fevereiro, Março, Abril e Maio. Foram observados sintomas da ferrugem alaranjada nos genótipos CTC 9, CV 14, RB93-5641, SP842025, RB72-454, SP89-1115, SP81-3250, RB85-5156, CTC 15, RB92-579, SP83-2847 e RB92-5211. Os genótipos SP84-2025 e CV 14 foram os mais suscetíveis à doença. Este trabalho contribui para aperfeiçoar o manejo integrado da ferrugem alaranjada no Brasil, além de auxiliar os programas de melhoramento visando à obtenção de novas variedades resistentes à doença.

Palavras-chave adicionais: Epidemiologia, Manejo integrado, Melhoramento genético.

\section{ABSTRACT}

Araújo, K.L.; Canteri, M.G.; Gilio, T.A.S.; Neubauer, R.A.; Sanches, P.B.; Sumida, C.H.; Giglioti, E.A. Genotypic resistance and monitoring of favorability for the occurrence of orange rust in sugarcane. Summa Phytopathologica, v.39, n.4, p.271-275, 2013.

Currently, orange rust is one of the major diseases affecting sugar cane. Yield losses above $40 \%$ have been recorded for susceptible and intermediate genotypes in different countries, including Brazil. This study was developed with the aim of monitoring the major sugar cane genotypes grown in Brazil under high inoculum pressure for the occurrence and the development of orange rust. The experiment was conducted in an experimental field of Univalem Plant, Group "Raizen S.A.", located in Valparaiso (São Paulo State). The adopted experimental design was in randomized blocks with 38 treatments (genotypes) and four replicates. Each plot consisted of three lines of five meters, spaced $1.4 \mathrm{~m}$ apart. A line of genotype CV14, susceptible to orange rust, was included between each plot. From plant emergence, all plots were monthly monitored to determine the onset of symptoms. Once the first symptoms were noted, the severity of orange rust was monthly quantified on leaf +3 in three plants per plot. The most favorable months for the occurrence of this disease were February, March, April and May. Orange rust symptoms were observed for genotypes CTC 9, CV 14, RB93-5641, SP84-2025, RB72-454, SP89-1115, SP81-3250, RB85-5156, CTC 15, RB92579, SP83-2847 and RB92-5211. Genotypes SP84-2025 and CV 14 were most susceptible to the disease. This study contributes to improving the integrated management of orange rust in Brazil and assists breeding programs aimed at producing new varieties resistant to this disease. 
O Brasil sempre teve tradição no cultivo de cana-de-açúcar e atualmente é o maior produtor desta cultura, respondendo por cerca de $40 \%$ da produção mundial (9). Um dos entraves para se lograr grandes produtividades é a ocorrência de doenças, incluindo a ferrugem alaranjada da cana-de-açúcar (8).

A ferrugem alaranjada da cana-de-açúcar, causada pelo fungo Puccinia kuehnii (W. Krüger) E.J. Butler foi sempre considerada uma doença de importância secundária no setor sucroalcooleiro até o final da década de 90. A doença estava restrita à Ásia e Oceania, sem registro de perdas significativas na produtividade e no acúmulo de açúcar. No entanto, durante a safra de 2000 na Austrália, alta severidade da ferrugem alaranjada foi observada na maioria dos campos comerciais da Q124, a variedade de cana mais cultivada naquele país (13). Em julho de 2007, a doença foi encontrada na Flórida (EUA) (7).

Em outubro de 2007, a ferrugem alaranjada foi observada na maioria dos campos comerciais de cana da América Central, incluindo a Guatemala (16), Nicarágua e Costa Rica (6). Em 2008, a doença foi também diagnosticada no México, no Panamá, em El Salvador e na Jamaica (10). Em julho de 2010, a ferrugem alaranjada foi confirmada em Valle Del Cauca, importante região canavieira da Colômbia (17). Em todos estes países, a ferrugem alaranjada causou significativa redução na produtividade e no acúmulo de açúcar.

No Brasil, a ferrugem alaranjada foi diagnosticada em dezembro de 2009, na região de Araraquara, no Estado de São Paulo (1). A partir de então, a doença se estabeleceu e se disseminou por todas as principais regiões canavieiras do país: São Paulo, Mato Grosso do Sul, Paraná, Espírito Santo, Goiás e Minas Gerais (5).

As perdas causadas pela ferrugem alaranjada da cana-de-açúcar têm atingido valores superiores a $50 \%$ em variedades suscetíveis. $\mathrm{Na}$ Austrália, foram estimadas perdas de rendimento superiores a $35 \%$ (13).

Essa doença tem causado motivos de preocupação e têm levado a procura por práticas e estratégias de manejo que sejam eficientes e economicamente viáveis. O presente trabalho foi desenvolvido com o objetivo de avaliar os principais genótipos de cana-de-açúcar quanto ao aparecimento e desenvolvimento da ferrugem alaranjada, visando fornecer suporte ao manejo integrado da doença no Brasil.

\section{MATERIAL E MÉTODOS}

O experimento foi conduzido em área experimental da Usina Univalem, do Grupo Raízen SA, localizada no Município de Valparaíso (SP), no período de 30 de julho de 2010 a 01 de agosto de 2012, sob sistema de cultivo "cana ano". A área experimental encontrava-se situada na latitude $21^{\circ} 19^{\prime} 15^{\prime \prime} \mathrm{S}$ e longitude $50^{\circ} 56^{\prime} 14^{\prime \prime}$ W.

O plantio foi realizado manualmente em julho de 2010 colocandose dois colmos corridos por sulco de plantio, perfazendo, assim, uma densidade mínima de 12 gemas. $\mathrm{m}^{-1}$. No momento do plantio foi realizada adubação química com $500 \mathrm{~kg} \cdot \mathrm{ha}^{-1}$ de NPK (5:25:25) e aplicação do inseticida tiametoxam $\left(0,6 \mathrm{~kg} \cdot \mathrm{ha}^{-1}\right)$ e do nematicida carbofurano (6,5 L.ha-1).

Foram monitorados os seguintes genótipos de cana-de-açúcar: RB85-5453, SP81-3250, RB85-5536, SP80-3280, RB96-6928, RB835054, PO-8862, RB92-579, CTC15, CTC17, RB92-5211, RB93-5744, IAC95-5000, CTC20, SP79-1011, RB97-7619, RB96-5902, RB845210, RB93-509, RB96-5602, RB96-5917, CTC4, RB92-8064, RB975952, RB93-7570, CTC2, RB85-5156, RB72-454, SP80-1842, SP832847, SP89-1115, RB85-7515, CTC9, RB85-5035, SP84-2025, RB93-

\section{1, CV14, RB83-5486.}

O delineamento experimental foi o de blocos casualizados com 38 tratamentos (genótipos) e quatro repetições. Cada parcela foi constituída por três linhas de cinco metros de comprimento cada, com espaçamento entre linha de 1,4 metros, ou seja, $21 \mathrm{~m}^{2}$. Entre cada parcela, foi intercalado o plantio de uma linha do genótipo suscetível CV14, como linha infectora. A inoculação das plantas do experimento ocorreu naturalmente. Os dados climáticos de temperatura e de umidade relativa do ar durante a condução do experimento foram obtidos do INMET (Instituto Nacional de Meteorologia), da estação de meteorológica instalada no município de Valparaíso-SP. De posse dos registros horários de temperatura e umidade relativa do ar durante o experimento, foi calculado o Índice de Favorabilidade Climática, ou seja, quantidade total de horas ótimas para a germinação dos esporos de P. kuehnii por mês. Como condições climáticas ideais foram consideradas temperaturas entre 17 e $24{ }^{\circ} \mathrm{C}$ e umidade relativa do ar maior ou igual a $95 \%$ (14).

Após constatados os primeiros sintomas da doença, a severidade foi estimada na folha +3 de três plantas por parcela. As avaliações de severidade foram realizadas mensalmente, durante o desenvolvimento de "cana planta". Para avaliar a ferrugem alaranjada, os avaliadores foram previamente treinados para o software COMBRO (4) e utilizaram uma escala diagramática modificada elaborada pela SCORALERT por ser uma escala mais adaptada para atividades que envolvem o manejo da ferrugem alaranjada e não só, testes de resistência de variedades. Com os valores médios de severidade da ferrugem alaranjada foram traçadas curvas de progresso da doença ao longo do ano para cada tratamento (genótipo). A área abaixo da curva de progresso da doença (AACPD) por tratamento foi calculada por integração trapezoidal (18). A variável AACPD foi dividida pelo respectivo período de duração da epidemia (AACPDes).

As curvas de progresso da doença obtidas de cada tratamento foram ajustadas aos modelos Logístico $\left[\mathrm{y}=1 /\left(1+\left(\left(1 / \mathrm{y}_{0}\right)-1\right) \exp (-\mathrm{rt})\right)\right]$ e Gompertz $\left[\mathrm{y}=\exp \left(-\left(-\ln \left(\mathrm{y}_{0}\right)\right) \exp (-\mathrm{rt})\right)\right]$, em que: $\mathrm{y}=$ estimativa da doença; $\mathrm{y}_{\mathrm{o}}=$ quantidade de inóculo inicial; $\mathrm{r}=$ taxa de progresso da doença específica para cada modelo $\mathrm{e} ; \mathrm{t}=$ tempo. $\mathrm{O}$ modelo de regressão considerado mais adequado aos dados obtidos foi selecionado considerando-se conjuntamente: (i) maior coeficiente de determinação ajustado $\left(\mathrm{R}^{* 2}\right)$, obtido da regressão linear entre os valores previstos pelos modelos (variável dependente) e os observados (variável independente), (ii) menor desvio padrão para o inóculo inicial e para a taxa de progresso da doença e (iii) menor variância e distribuição mais aleatória dos erros (severidade observada menos severidade estimada pelo modelo) (3).

Os dados da AACPDes obtidos de cada tratamento foram submetidos à análise de variância, e as médias, quando significativas, foram comparadas pelo teste de agrupamento Scott-Knott ao nível de $5 \%$ de probabilidade. Utilizou-se o programa SAEG (Sistema de Análises Estatísticas e Genéticas, Universidade Federal de Viçosa) para a análise dos dados.

\section{RESULTADOS E DISCUSSÃO}

Para as condições de Valparaíso - SP, dos 38 genótipos monitorados durante o experimento, os sintomas da ferrugem alaranjada foram observados em SP81-3250, RB92-579, CTC15, RB92-5211, RB977619, RB93-509, RB85-5156, RB72-454, SP89-1115, CTC9, SP842025, RB93-5641 e CV14. Os primeiros sintomas da ferrugem alaranjada foram observados apenas no mês de março de 2011, cerca 
de 235 dias após o plantio (Figura 1A). Nos genótipos RB93-509, RB92-579 e RB97-7619, houve um atraso no início da epidemia, sendo os primeiros sintomas observados apenas em abril de 2011. Depois de constatado esses sintomas iniciais, o progresso da doença foi mais acentuado nos genótipos SP84-2025 e CV 14. Nos genótipos RB97-7619, RB93-509, CTC 9, CTC 15 e SP81-3250, embora tenha sido constatado sintomas da doença, a severidade registrada foi baixa, com valores médios inferiores a $2 \%$ em todas as avaliações (Figura 1A).

Embora não tenham sido observados sintomas da doença nos estádios iniciais de desenvolvimento dos genótipos, aparentemente o progresso da ferrugem alaranjada não está relacionado ao estádio fenológico da cana-de-açúcar, sendo altamente dependente das condições climáticas locais. A não ocorrência da ferrugem alaranjada nos primeiros sete meses de cultivo dos genótipos, provavelmente, está ligada a baixa favorabilidade climática ao desenvolvimento da doença registrada na região de Agosto de 2010 a Janeiro de 2011 (Figura 1B).

Analisando-se as curvas de progresso da doença (Figura 1A) e o progresso da favorabilidade climática ao desenvolvimento da doença
(Figura 1B), observou-se que o aparecimento e desenvolvimento da doença nos genótipos coincidiram com o aumento no número de horas favoráveis a germinação dos esporos registrados de Fevereiro a Maio de 2011. Ao longo do mês de Fevereiro, Março, Abril e Maio foram registrados, respectivamente, 160,117, 100 e 80 horas favoráveis ao desenvolvimento da ferrugem alaranjada (Figura 1B).

O modelo para o cálculo da favorabilidade baseou-se nas condições ótimas para a germinação dos esporos do fungo P. kuehnii (14) e permitiu observar relação entre aumento da favorabilidade climática e aumento da intensidade da doença no campo, corroborando com trabalhos anteriores de Staier et al. (19) na Austrália. Minchio et al. (15) observaram germinação de esporos de P. kuehnii na faixa de temperatura de 10 a $30^{\circ} \mathrm{C}$, porém, os valores máximos de germinação foram observados à temperatura de $21{ }^{\circ} \mathrm{C}$ com período de incubação de 14 horas.

Analisando-se os valores dos coeficientes de determinação $\left(\mathrm{R}^{* 2}\right)$, do desvio padrão do inóculo inicial $\left(\mathrm{DPy}_{0}\right)$ e do desvio padrão da taxa de progresso da doença (DPr) obtidos dos modelos Logístico e Gompertz para cada genótipo (Tabela 1), foi possível perceber que o modelo Gompertz foi o que melhor se ajustou ao conjunto de dados,

A

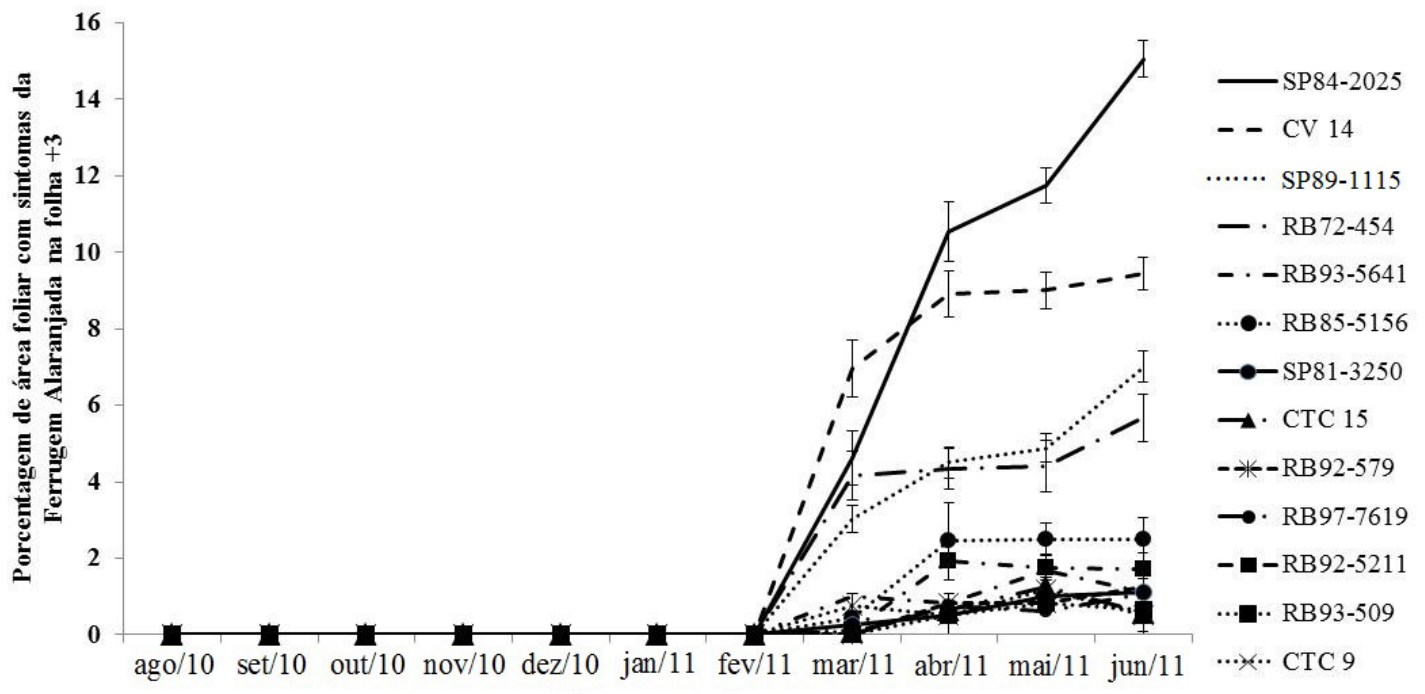

B

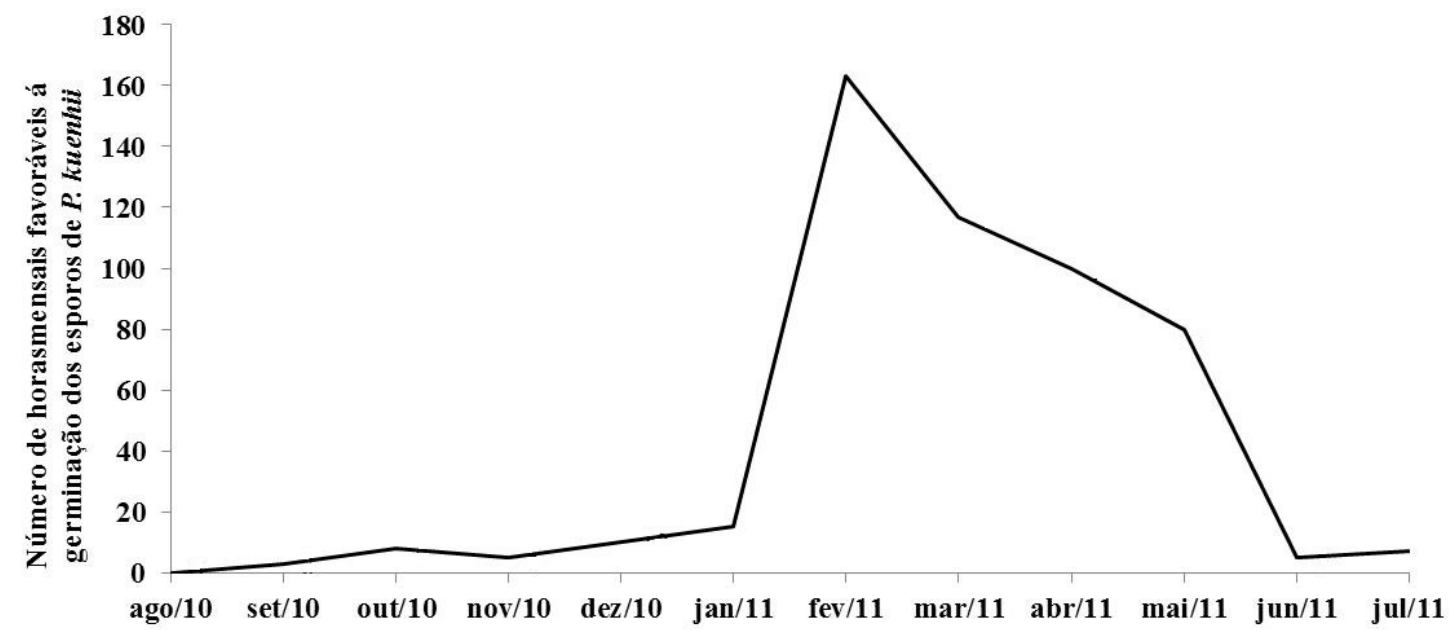

Figura 1. Curvas de Progresso da ferrugem alaranjada obtida nos genótipos de cana-de-açúcar (A) e curva de favorabilidade climática ao desenvolvimento da ferrugem alaranjada da cana-de-açúcar (B). 
apresentando um maior $\mathrm{R}^{* 2}(0,722)$, menor $\mathrm{DPy}_{0}(0,0002)$ e menor $\mathrm{DPr}(0,0003)$ (3) em comparação com os valores médios apresentados pelo modelo Logístico (Tabela 1), respectivamente, 0,650, 0,0004 e 0,0017. Entretanto, os ajustes do modelo Gompertz aos dados de severidade dos genótipos SP81-3250, RB92-579, CTC15, RB97-7619, RB93-509, CTC9 e RB93-5641 proporcionaram $\mathrm{R}^{* 2}$ inferior a 80\%, indicando que o modelo utilizado não foi adequado para descrever curvas de progresso da ferrugem alaranjada nesses genótipos (3).

Como não houve ajuste de um único modelo às curvas de progresso da ferrugem alaranjada, os tratamentos foram comparados utilizandose Área Abaixo da Curva de Progresso da doença estandardizada (AACPDes) (Tabela 2). A média dos valores da AACPDes nas folhas +3 dos genótipos que apresentaram sintomas da ferrugem alaranjada variou de 10,79 a 0,73 . Por meio do teste de Scott-Knott aplicado a AACPDes, foi possível perceber a formação de oito agrupamentos de genótipos de cana-de-açúcar referentes a diferentes níveis de resistência/ suscetibilidade à ferrugem alaranjada (Tabela 2).

AAACPDes foi significativamente $(\mathrm{p}<0,05)$ maior nos genótipos SP84-2025 (10,79) e CV $14(9,30)$ que, por este motivo, foram classificadas como altamente suscetíveis à ferrugem alaranjada, seguidos pela RB72-454 $(6,10)$ e SP89-1115 $(4,98)$ classificadas como suscetíveis (Tabela 2).

Tabela 1. Valores do coeficiente de determinação ajustado $\left(\mathrm{R}^{2 *}\right)$, desvio padrão do inóculo inicial $\left(\mathrm{DPy}_{0}\right)$ e desvio padrão da taxa de progresso (DPr) após ajuste dos modelos Logistico e Gompertz aos dados de severidade da ferrugem alaranjada da cana-de-açúcar. Valparaíso-SP, 2010/2011.

\begin{tabular}{|c|c|c|c|c|}
\hline Genótipos & Modelo & $\mathbf{R}^{2^{*}}$ & $\mathrm{DPy}_{0}$ & DPr \\
\hline \multirow[t]{2}{*}{ SP84-2025 } & Logístico & 0,8858 & 0,00075 & 0,00104 \\
\hline & Gompertz & 0,9129 & 0,00009 & 0,00031 \\
\hline \multirow[t]{2}{*}{ CV14 } & Logístico & 0,7110 & 0,00148 & 0,00120 \\
\hline & Gompertz & 0,8113 & 0,00070 & 0,00035 \\
\hline \multirow[t]{2}{*}{ RB72-454 } & Logístico & 0,8459 & 0,00029 & 0,00157 \\
\hline & Gompertz & 0,8578 & 0,00003 & 0,00044 \\
\hline \multirow[t]{2}{*}{ SP89-1115 } & Logístico & 0,8980 & 0,00042 & 0,00101 \\
\hline & Gompertz & 0,8980 & 0,00013 & 0,00025 \\
\hline \multirow[t]{2}{*}{ RB92-5211 } & Logístico & 0,5367 & 0,00032 & 0,00191 \\
\hline & Gompertz & 0,8689 & 0,00018 & 0,00038 \\
\hline \multirow[t]{2}{*}{ RB85-5156 } & Logístico & 0,6304 & 0,00031 & 0,00154 \\
\hline & Gompertz & 0,8304 & 0,00014 & 0,00033 \\
\hline \multirow[t]{2}{*}{ RB93-5641 } & Logístico & 0,5164 & 0,00035 & 0,00198 \\
\hline & Gompertz & 0,6982 & 0,00024 & 0,00039 \\
\hline \multirow[t]{2}{*}{ RB92-579 } & Logístico & 0,7260 & 0,00006 & 0,00182 \\
\hline & Gompertz & 0,7315 & 0,00010 & 0,00033 \\
\hline \multirow[t]{2}{*}{ RB97-7619 } & Logístico & 0,7315 & 0,00006 & 0,00214 \\
\hline & Gompertz & 0,7443 & 0,00002 & 0,00038 \\
\hline \multirow[t]{2}{*}{ RB93-509 } & Logístico & 0,5000 & 0,00011 & 0,00281 \\
\hline & Gompertz & 0,5366 & 0,00004 & 0,00049 \\
\hline \multirow[t]{2}{*}{ СТC9 } & Logístico & 0,4378 & 0,00030 & 0,00205 \\
\hline & Gompertz & 0,4276 & 0,00025 & 0,00037 \\
\hline \multirow[t]{2}{*}{ CTC15 } & Logístico & 0,5161 & 0,00018 & 0,00227 \\
\hline & Gompertz & 0,5338 & 0,00011 & 0,00041 \\
\hline \multirow[t]{2}{*}{ SP81-3250 } & Logístico & 0,5161 & 0,00008 & 0,00110 \\
\hline & Gompertz & 0,5338 & 0,00006 & 0,00018 \\
\hline
\end{tabular}

Tabela 2. Área Abaixo da Curva de Progresso da Ferrugem alaranjada Estandardizada (AACPDes) na folha +3 e nível de resistência dos genótipos de cana-de-açúcar.

\begin{tabular}{|c|c|c|c|}
\hline Tratamento & Genótipos & AACPDes & Nível de resistência \\
\hline 1 & SP84-2025 & $10,79 \mathrm{a}$ & Altamente suscetível \\
\hline 2 & CV14 & $9,30 \mathrm{~b}$ & Altamente suscetível \\
\hline 3 & RB72-454 & $6,10 \mathrm{c}$ & Suscetível \\
\hline 4 & SP89-1115 & $4,98 \mathrm{~d}$ & Suscetível \\
\hline 5 & RB92-5211 & $2,30 \mathrm{e}$ & Moderadamente suscetível \\
\hline 6 & RB $85-5156$ & $2,18 \mathrm{e}$ & Moderadamente suscetível \\
\hline 7 & RB93-5641 & $1,27 \mathrm{f}$ & Moderadamente resistente \\
\hline 8 & RB92-579 & $1,12 \mathrm{f}$ & Moderadamente resistente \\
\hline 9 & RB97-7619 & $0,93 \mathrm{~g}$ & Moderadamente resistente \\
\hline 10 & RB93-509 & $0,82 \mathrm{~g}$ & Moderadamente resistente \\
\hline 11 & CTC 9 & $0,83 \mathrm{~g}$ & Moderadamente resistente \\
\hline 12 & CTC 15 & $0,76 \mathrm{~g}$ & Moderadamente resistente \\
\hline 13 & SP81-3250 & $0,73 \mathrm{~g}$ & Moderadamente resistente \\
\hline 14 & RB85-5453 & $0 \mathrm{~h}$ & Resistente \\
\hline 15 & RB85-5536 & $0 \mathrm{~h}$ & Resistente \\
\hline 16 & SP80-3280 & $0 \mathrm{~h}$ & Resistente \\
\hline 17 & RB96-6928 & $0 \mathrm{~h}$ & Resistente \\
\hline 18 & RB83-5054 & $0 \mathrm{~h}$ & Resistente \\
\hline 19 & PO8862 & $0 \mathrm{~h}$ & Resistente \\
\hline 20 & CTC 17 & $0 \mathrm{~h}$ & Resistente \\
\hline 21 & RB93-5744 & $0 \mathrm{~h}$ & Resistente \\
\hline 22 & IAC95-5000 & $0 \mathrm{~h}$ & Resistente \\
\hline 23 & СТC20 & $0 \mathrm{~h}$ & Resistente \\
\hline 24 & SP79-1011 & $0 \mathrm{~h}$ & Resistente \\
\hline 25 & RB96-5902 & $0 \mathrm{~h}$ & Resistente \\
\hline 26 & RB84-5210 & $0 \mathrm{~h}$ & Resistente \\
\hline 27 & RB96-5602 & $0 \mathrm{~h}$ & Resistente \\
\hline 28 & RB96-5917 & $0 \mathrm{~h}$ & Resistente \\
\hline 29 & CTC4 & $0 \mathrm{~h}$ & Resistente \\
\hline 30 & RB92-8064 & $0 \mathrm{~h}$ & Resistente \\
\hline 31 & RB97-5952 & $0 \mathrm{~h}$ & Resistente \\
\hline 32 & RB93-7570 & $0 \mathrm{~h}$ & Resistente \\
\hline 33 & CTC2 & $0 \mathrm{~h}$ & Resistente \\
\hline 34 & RB85-7515 & $0 \mathrm{~h}$ & Resistente \\
\hline 35 & SP83-2847 & $0 \mathrm{~h}$ & Resistente \\
\hline 36 & SP80-1842 & $0 \mathrm{~h}$ & Resistente \\
\hline 37 & RB85-5035 & $0 \mathrm{~h}$ & Resistente \\
\hline \multirow[t]{2}{*}{38} & RB83-5486 & $0 \mathrm{~h}$ & Resistente \\
\hline & $\mathrm{CV} \%$ & 17,11 & \\
\hline
\end{tabular}

*Medias seguidas da mesma letra não difere entre si pelo teste de agrupamento Scott-knott. ao nível de $5 \%$ de significância.

Recomenda-se evitar o cultivo desses quatro genótipos, porém a substituição de cultivares deverá ser racional, respeitando-se os cortes necessários para diluir os custos do plantio, podendo-se utilizar controle químico da doença até a renovação do canavial. Os genótipos RB92-5211 (2,30) e RB85-5156 (2,18) formaram um grupo estatisticamente diferente, sendo considerados moderadamente suscetíveis à ferrugem alaranjada (Tabela 2). Os genótipos RB93- 
5641, RB92-579, RB97-7619, RB93-509, CTC 9, CTC 15 e SP813250 foram considerados moderadamente resistentes, pois, os valores da AACPDes foram significativamente $(\mathrm{p}<0,05)$ inferiores aos obtidos nos genótipos SP84-2025, CV 14, RB72-454, SP89-1115, RB92-5211 e RB85-5156 (Tabela 2). Como a severidade das ferrugens em canade-açúcar é favorecida não só pelas condições climáticas, mas também por solos mais pesados e férteis, adubação nitrogenada, fertirrigação com vinhaça, utilização de torta de filtro e colheita tardia (11), os genótipos de resistência intermediária podem, em muitos casos, apresentar níveis epidêmicos da doença, sendo recomendado nessas condições, o uso de controle químico. Portanto, o cultivo desses genótipos deve ser evitado em condições de manejo que favoreceram a ocorrência da ferrugem alaranjada.

Nos genótipos RB85-5453, RB85-5536, SP80-3280, RB96-6928, RB83-5054, PO-8862, CTC17, RB93-5744, IAC95-5000, CTC20, SP79-1011, RB96-5902, RB84-5210, RB96-5602, RB96-5917, CTC4, RB92-8064, RB97-5952, RB93-7570, CTC2, SP80-1842, SP83-2847, RB85-7515, RB85-5035 e RB83-5486 não foram constatados sintomas da ferrugem alaranjada em nenhuma das avaliações realizadas (Tabela 2). Esses genótipos foram considerados resistentes ao patógeno. Mesmo não tendo sido constatados sintomas da doença nesses genótipos nas condições de Valparaíso-SP, é importante o monitoramento constante dos mesmos, pois genótipos resistentes podem se tornar suscetíveis ao longo do tempo devido à existência de variabilidade na população do patógeno (13). A existência de variabilidade entre isolados de $P$. kuehnii já foi relatada por Braithwaite et al. (2) e Glynn et al. (12), assim, há a possibilidade de ocorrência de raças do patógeno e, consequentemente, a reação de resistência das cultivares de cana-de-açúcar podem mudar futuramente. Além disso, é importante o monitoramento dos genótipos de cana-de-açúcar em outras regiões, pois, como demonstrado neste trabalho, as condições climáticas influenciam o aparecimento e o desenvolvimento da ferrugem alaranjada da cana-de-açúcar.

\section{AGRADECIMENTOS}

À Coordenação de Aperfeiçoamento de Pessoal de Nível Superior (Capes) e ao Conselho Nacional de Desenvolvimento Científico e Tecnológico (CNPq) pela concessão de bolsas aos autores.

Ao Grupo Raízen por ceder a área e todo o suporte para a implantação, condução e avaliação do presente experimento.

\section{REFERÊNCIAS}

1. Barbasso, D.; Jordão, H.; Maccheroni, W.; Boldini, J.; Bressiani, J.; Sanguino, A. First Report of Puccinia kuehnii causal agent of orange rust of sugarcane in Brazil. Plant Disease, St. Paul, v. 94, p. $1170,2010$.

2. Braithwaite, K. S.; Croft, B. J.; Magarey, R. C.; Scharaschkin, T. Phylogenetic placement of the sugarcane orange rust pathogen Puccinia kuehnii in a historical and regional context. Australasian Plant Pathology, Queensland, v. 38, n. 4, p. 380-388, 2009.

3. Campbell, C. L.; Madden, L. V. Introduction to plant disease epidemiology. New York: John Wiley, 1990. 532 p.

4. Canteri, M. G.; Giglioti, E. A. COMBRO: um software para sele- ção e treinamento de avaliadores de ferrugem e do complexo broca-podridões em cana-de-açúcar. Summa Phytopathologica, Jaboticabal, v. 24, n 2, p. 190-192, 1998.

5. Centro de Tecnologia Canavieira. Mapa das ocorrências da ferrugem alaranjada. São Paulo, 2011. Disponível em: <http:// www.ctcanavieira.com.br/index.php? option=com_content\&view= article $\& i d=507$ :ferrugem-alaranjada-da-cana-de-acuca rmapadeocorrencias \&catid $=3:$ destaque $\&$ Itemid $=1460>$. Acesso em: 25 abr. 2012.

6. Chavarría, E.; Subirós, F.; Veja, J.; Ralda, G.; Glynn, N. C.; Comstock. J. C.; Castlebury, L.A. First report of orange rust of sugarcane caused by Puccinia kuehnii in Costa Rica and Nicaragua, Plant Disease, St. Paul, v. 93, p. 425-425, 2009.

7. Comstock, J. C.; Sood, S. G.; Glynn, N. C.; Shine Jr, J. M.; Mckemy, J. M.; Castlebury, L. A. First report of Puccinia kuehnii causal agent of Orange Rust of Sugarcane in the United States and Western Hemisphere. Plant Disease, St. Paul, v. 92, p. 175, 2008.

8. Dinardo-Miranda, L. L.; Vasconcelos, A. C. M.; Landell, M. G. Canade-Açúcar. Campinas: Instituto Agronômico \& Fundação IAC, 2008. p. 882 .

9. FAO. Statístics Division of the Fao. Disponível em: <http:// faostat.fao.org/ site/567/DesktopDefault.aspx ?PageID= 567\#ancor>. Acesso em: 29 ago. 2013.

10. Flores, R. C.; Loyo, J. R.; Ojeda, R. A.; Rangel, O. C. A. First report of orange rust of sugarcane caused by Puccinia kuehnii in Mexico, El Salvador and Panama. Plant Disease, St. Paul, v. 93, p. $1347,2009$.

11. Giglioti, E. A.; Zavaglia, L. P.; Menezes, L. L.; Moura, G. L.; Matsuoka, S. Resistência e tolerância à ferrugem da canade-açúcar: o caso da RB835486. Araras: Universidade Federal de São Carlos, 1999. 10 p.

12. Glynn, N. C.; Dixon, L. J.; Castlebury, L. A.; Szabo, L. J.; Comstock, J. C. PCR assays for the sugarcane rust pathogens Puccinia kuehnii and P. melanocephala and detection of a SNP associated with geographical distribution in P. kuehnii. Plant Pathology, St. Paul, v. 59, p. 703-711, 2010.

13. Magarey, R.; Willcox, T.; Croft, B.; Cordingley. A. Orange rust, a major pathogen affecting crops of Q124 in Queensland in 2000. Proceedings of the Australian Society of Sugar Cane Technologists, Mackay, v. 23, p. 274-280, 2001.

14. Magarey, R. C.; Neilsen, W. A.; Magnanini, A. J. Environmental requirements for spore germination in three sugarcane leaf pathogens. Proceedings of the Australian Society of Sugar Cane Technologists, Mackay, v. 33, p. 307-315, 2004.

15. Minchio, C. A.; Canteri, M. G.; Rocha, J. A. Germination of uredospores of Puccinia kuehnii subjected to different temperatures and incubation times. Summa Phytopathologica, Botucatu, v. 37, n.4, p. 211-214, 2011.

16. Ovalle, W.; Comstock. J. C.; Glynn, N. C.; Castlebury, L. A. First report of Puccinia kuehnii causal agent of orange rust of sugarcane in Guatemala. Plant Disease, St. Paul, v. 92, p. 973-973, 2008.

17. Sánchez, J. C. A.; Ordóñez, M. C.; Kafure, J. I. V. Presencia de Roya Naranja (Puccinia kuehnii em El Valle Del Cauca y estratégias para su manejo. 2010. Disponível em: <http:// www.cenicana.org/pdf/documentos_de_trabajo/doc_trabajo _ 715.pdf>. Acesso em: 24 ago. 2013.

18. Shaner, G.; Finney, R. E. The effect of nitrogen fertilization on the expression of slow-mildewing resistence in knox wheat. Phytopathology, St. Paul, v. 67, p. 1051-1056, 1977.

19. Staier, T. N.; Margarey, R. C.; Finlayson, W. A. Meteorological data collection analysis and sugarcane disease forecasting for orange rust. Proceedings of the Conference of the Australian Society of Sugar Cane Technology. Mackay, v. 26, p. 1-6, 2004. 